\title{
Promising PEGylated cationic dendrimers for delivery of miRNAs as a possible therapy against HIV-1 infection
}

\author{
E. Royo-Rubio ${ }^{1,2+}$, I. Rodríguez-Izquierdo ${ }^{1,2+}$, M. Moreno-Domene ${ }^{3}$, T. Lozano-Cruz ${ }^{4,5}$, F. J. de la Mata ${ }^{4,5}$, \\ R. Gómez ${ }^{4,5}$, M. A. Muñoz-Fernández ${ }^{1 *}$ (1) and J. L. Jiménez ${ }^{2^{*}}$ (1)
}

\begin{abstract}
Background: The appearance of resistance against new treatments and the fact that HIV-1 can infect various cell types and develop reservoirs and sanctuaries makes it necessary to develop new therapeutic approaches to overcome those failures.

Results: Studies of cytotoxicity, genotoxicity, complexes formation, stability, resistance, release and particle size distribution confirmed that G2-SN15-PEG, G3-SN31-PEG, G2-SN15-PEG-FITC and G3-SN31-PEG-FITC dendrimers can form complexes with miRNAs being biocompatible, stable and conferring protection to these nucleic acids. Confocal microscopy and flow cytometry showed effective delivery of these four dendrimers into the target cells, confirming their applicability as delivery systems. Dendriplexes formed with the dendrimers and miRNAs significantly inhibited HIV-1 infection in PBMCs.
\end{abstract}

Conclusions: These dendrimers are efficient delivery systems for miRNAs and they specifically and significantly improved the anti-R5-HIV-1 activity of these RNA molecules.

Keyword: Carbosilane dendrimers, microRNAs, HIV-1 infection, Delivery, Inhibition

\section{Background}

Human Immunodeficiency Virus (HIV) infection mainly affects CD4 $+\mathrm{T}$ lymphocytes, dendritic cells and macrophages [1]. Moreover, there is a wide range of cellular types susceptible to HIV-1 infection, such as central nervous system (CNS) cells including microglia or astrocytes [2]. Lymphocytes are mainly located in the

\footnotetext{
*Correspondence: mmunoz.hgugm@salud.madrid.org; joseluis. jimenez@salud.madrid.org

${ }^{\dagger}$ E. Royo-Rubio and I. Rodríguez-Izquierdo contributed equally to this work

${ }^{1}$ Laboratorio InmunoBiología Molecular, Hospital General Universitario Gregorio Marañón (HGUGM), Instituto Investigación Sanitaria Gregorio Marañón (liSGM), Spanish HIV HGM BioBanco, Madrid, Spain

2 Plataforma de Laboratorio (Inmunología), HGUGM, liSGM, Spanish HIV HGM BioBank, Madrid, Spain

Full list of author information is available at the end of the article
}

circulatory system and lymphatic ganglions whereas dendritic cells and macrophages play a key role in the immune surveillance of mucosa and tissues. Current treatments against HIV-1 infection control viral replication and disease progression. These treatment combinations mainly include integrase inhibitors such as abacavir, lamivudine, tenofovir alafenamide or emtricitabine, or nucleoside reverse transcriptase inhibitors (NRTIs) such as bictegravir, dolutegravir or raltegravir [3, 4]. Combined therapy includes at least three of these drugs reducing the appearance of mutations and increasing the virological failure. However, the appearance of resistance against these new treatments, mainly in low- and middleincome countries [5-7] and the fact that HIV-1 can infect a wide range of cells and develop sanctuaries and reservoirs [8-11] bring to light the need of new possible therapeutic approaches to eliminate those failures. 
Different delivery nanocarriers provide a scaffold through which different small RNA molecules have been successfully delivered in diverse studies [12-15]. We have carried out broad research about various dendrimers in the context of HIV-1 infection [16-20]. Previously, we reported amino-terminated carbosilane dendrimers that provide stability, protection and high transfection efficiency to oligodeoxynucleotides and siRNAs inhibiting HIV-1 replication in peripheral blood mononuclear cells (PBMCs) and CD4 T-cells [21-24]. Carbosilane dendrimers are three-dimensional hyperbranched molecules capable of forming complexes by electrostatic interactions between the positively charged functional terminal groups and negatively charged backbone of small RNAs, what confers protection and facilitates transfection of bound RNAs [25].

Novel therapeutic strategies are being developed from the study of HIV-host interactions, for example microRNAs able to target HIV-1 infection and replication [26]. These miRNAs are small non-coding RNAs, 19-25 long nucleotides, with capability to modulate gene expression at post-transcriptional level [27]. A wide range of different cellular miRNAs has been described to have a negative impact on HIV-1 replication through repressing its expression by targeting HIV-1 3'-UTR or enhancing HIV-1 mRNA interactions with RISC complex [28-30]. The effective delivery of these miRNAs is a limiting factor in their therapeutic applications since naked miRNAs face several difficulties when navigating the circulatory system such as phagocytosis, enzymatic degradation or protein aggregation [31]. Nanotechnology is a promising strategy for the delivery of small RNAs. In this work, G2-SN15-PEG, G3-SN31-PEG, G2-SN15-PEG FITC and G3-SN31-PEG FITC with PEG modifications, were selected. These four carbosilane dendrimers present different PEGylation residues to reduce toxicity and improve the biocompatibility of molecules [32]. Our objective was to form cationic dendrimers-miRNAs complexes that improved the therapeutic effect of current treatments against HIV-1 infection in different cells. We report the potential therapeutic effect of complexation of PEGylated G2-SN15-PEG, G3-SN31-PEG, G2-SN15-PEG-FITC and G3-SN31-PEG-FITC cationic dendrimers with hsa-miR29a-3p, hsa-miR-29b-3p, hsa-miR-92a-3p, hsa-miR-133b and hsa-miR-149-5p miRNAs in peripheral blood mononuclear cells (PBMCs) and U87MG-CD $4^{+} \mathrm{CCR} 5^{+}$cell line with anti-HIV-1 activity [33, 34]. First, the biosafety of four cationic dendrimers in PBMCs and l cell line were assessed by measuring cytotoxicity and genetic safety. We characterized several parameters of dendrimers-miRNAs (dendriplexes) formed to determine their stability, resistance to RNases and release capability. The internalization effectiveness of FITC-labelled dendrimers in PBMCs and U87MG-CD $4^{+} \mathrm{CCR} 5{ }^{+}$cell line was studied. Finally, HIV-1 inhibition capacity of dendriplexes in PBMCs and U87MG-CD $4{ }^{+} \mathrm{CCR} 5^{+}$cell was determined.

\section{Results \\ Cytotoxicity of the dendrimers on PBMCs and U87MG-CD4 ${ }^{+} \mathrm{CCR}^{+}$cell line}

Cytotoxicity of G2-SN15-PEG, G3-SN31-PEG, G2-SN15PEG FITC and G3-SN31-PEG FITC cationic dendrimers in PBMCs and U87MG-CD4 ${ }^{+} \mathrm{CCR}^{+}$cells was evaluated analyzing the mitochondrial toxicity by the 3-(4-5-dimethylthiazol-2-yl)-2,5-diphenyltetrazolium bromide (MTT) assay. PBMCs and U87MG-CD4 ${ }^{+}$CCR5 ${ }^{+}$ cells were treated with increasing concentrations of dendrimers, ranging from 0.01 to $30 \mu \mathrm{M}$, for $72 \mathrm{~h}$. Culture medium was used as non-treated control and DMSO $10 \%$ as death control. Non-toxic concentrations were considered when the survival rate was $\geq 80 \%$. Our data indicated that G2-SN15-PEG, G3-SN31-PEG, G2-SN15PEG FITC and G3-SN31-PEG FITC dendrimers were non-toxic in PBMCs at concentrations of 10, 5, 5 and $1 \mu \mathrm{M}$, respectively (Fig. 1a) and non-toxic in U87MG$\mathrm{CD}^{+}{ }^{+} \mathrm{CCR} 5^{+}$cells up at concentrations of $5,1,1$ and $0.5 \mu \mathrm{M}$, respectively (Fig. 1b).

\section{Genotoxicity of cationic dendrimers}

If dendrimers generated genotoxicity by interfering with the host genome by sister-chromatid exchange (SCE) assay was studied. It is important to note that dendrimers can bind to miRNAs as well as to host genome due to their positively charged functional groups. If these cationic dendrimers mistakenly targeted the host genome it could cause dangerous genetic changes to its stability. Therefore, it is recommended to perform genetic studies to rule out this event. The SCE assay detects the physical exchange of DNA that occurs between two identical chromatids in the chromosome, determining the genetic damage caused by treatments which persist after the DNA duplication [35-37]. Due to the fact that only fluorochrome unlabeled cationic dendrimers can be used in some studies, genotoxicity tests for G2-SN15PEG and G3-SN31-PEG cationic dendrimers were performed. PBMCs from five healthy donors were treated with G2-SN15-PEG $10 \mu \mathrm{M}$ or G3-SN31-PEG $5 \mu \mathrm{M}$ carbosilane cationic dendrimers for $72 \mathrm{~h}$ in presence of 5-bromo-2'-deoxyuridine (BdrU) following fluorescent plus Giemsa stain (FPG) (Fig. 2a). Non-treated samples and a dose of 1 Gy of radiation were used as untreated and genotoxicity control, respectively. Carbosilane cationic dendrimers did not generate genetic toxicity in PBMCs, since there are no significant differences among the non-treated and treated control samples, contrarily 

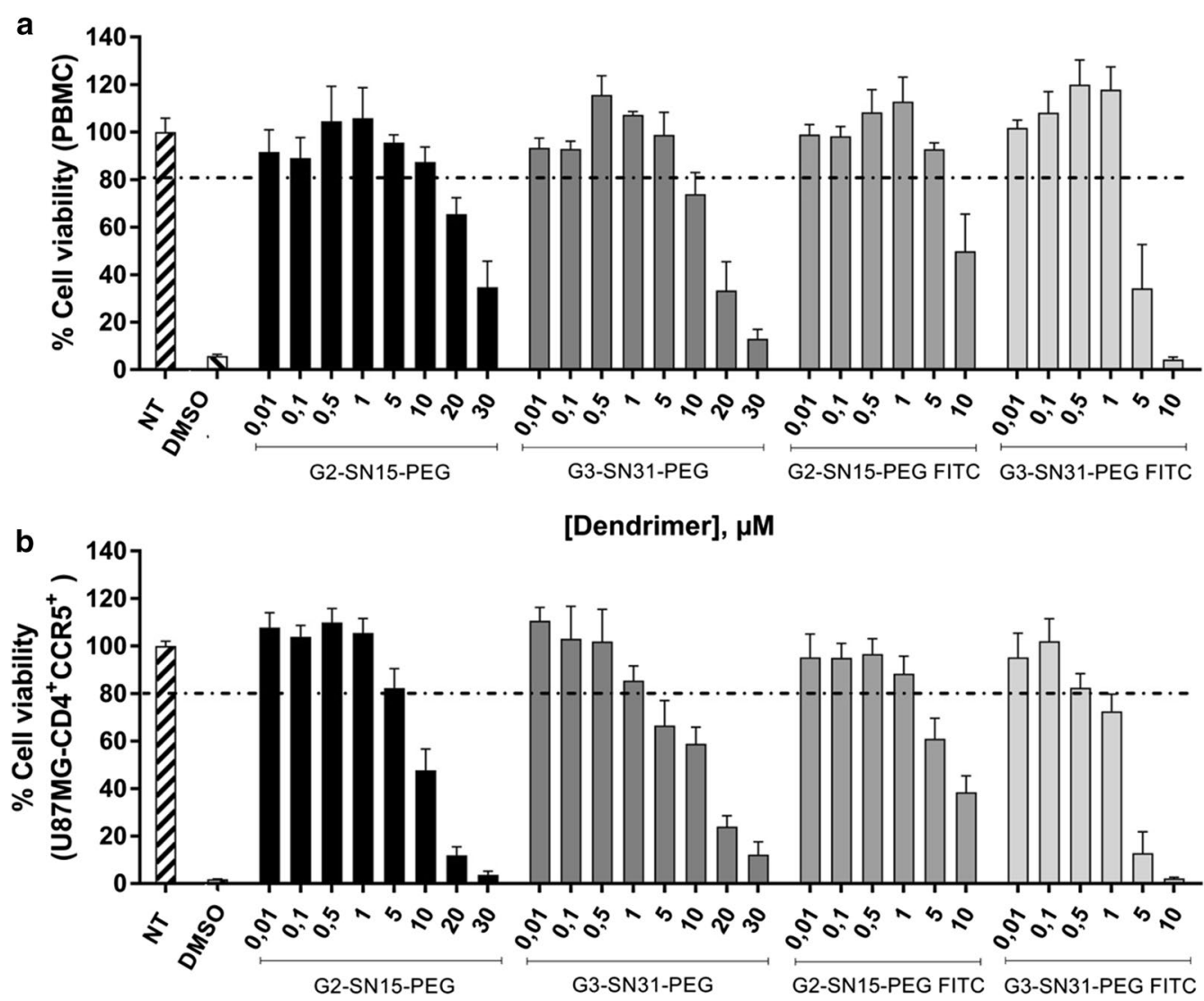

[Dendrimer], $\mu \mathrm{M}$

Fig. 1 Cytotoxicity of cationic carbosilane dendrimers by MTT assay. PBMCs (a) and U87MG-CD4 ${ }^{+} C C R 5^{+}$cells $(\mathbf{b})$ were treated in a range of concentrations from 0.01 to $30 \mu \mathrm{M}$ of each cationic dendrimer. Cell viability $>80 \%$ was established as non-toxic concentration. Culture medium samples were used as cell viability control and DMSO 10\% was used as death control. Data represented as mean \pm SD of three individual experiments performed in triplicate. DMSO dimethyl sulfoxide 10\%, NT non-treated

to what happens in genotoxicity control studied (Fig. 2b; Table 1).

\section{Dendriplexes formation and characterization}

First of all, whether unlabeled or FITC-labelled dendrimers could form dendriplexes with the studied miRNAs, were explored. Dendrimers were used at the maximal non-toxic concentrations and dendrimers-miRNAs complexes were analyzed using $2 \%$ agarose gel. After $2 \mathrm{~h}$ of incubation, G2-SN15-PEG and G3-SN31-PEG dendrimers efficiently bound $99 \%$ of miRNA with stable binding up to $48 \mathrm{~h}$ (Fig. 3a, b). When dendrimer concentrations were lowered to match maximal non-toxic concentrations for U87MG-CD $4{ }^{+} \mathrm{CCR} 5^{+}$cells, similar results were found. G2-SN15-PEG and G3-SN31-PEG dendrimers bound around $90 \%$ and $80 \%$ of siRNAs, respectively, confirming that both dendrimers can perform and efficient and stable bond with these miRNAs (Fig. 3c-f).
Heparin competition and RNase protection assays

We first analyzed whether miRNAs were released by conducting heparin competition assays. miRNAs were released after heparin treatment, demonstrating that miRNAs could be released from the dendrimer. We also analyzed whether miRNA dendrimer binding protected miRNAs from RNase-mediated degradation, showing that dendrimers confer protection since miRNAs were completely recovered after treatment with RNases followed by heparin (Fig. 4a, b).

Dendriplexes were prepared with miRNA control $2 \mathrm{~h}$ before being treated with heparin and/or RNases. Dendrimers concentrations were (a) G2-SN15-PEG $10 \mu \mathrm{M}$ and G3-SN31-PEG $5 \mu \mathrm{M}$, or (b) G2-SN15-PEG $5 \mu \mathrm{M}$ and G3-SN31-PEG $1 \mu \mathrm{M}$.

\section{Zeta potential and dynamic light scattering}

To evaluate how miRNAs affects the properties of the dendrimer we studied the surface charge and stability by 

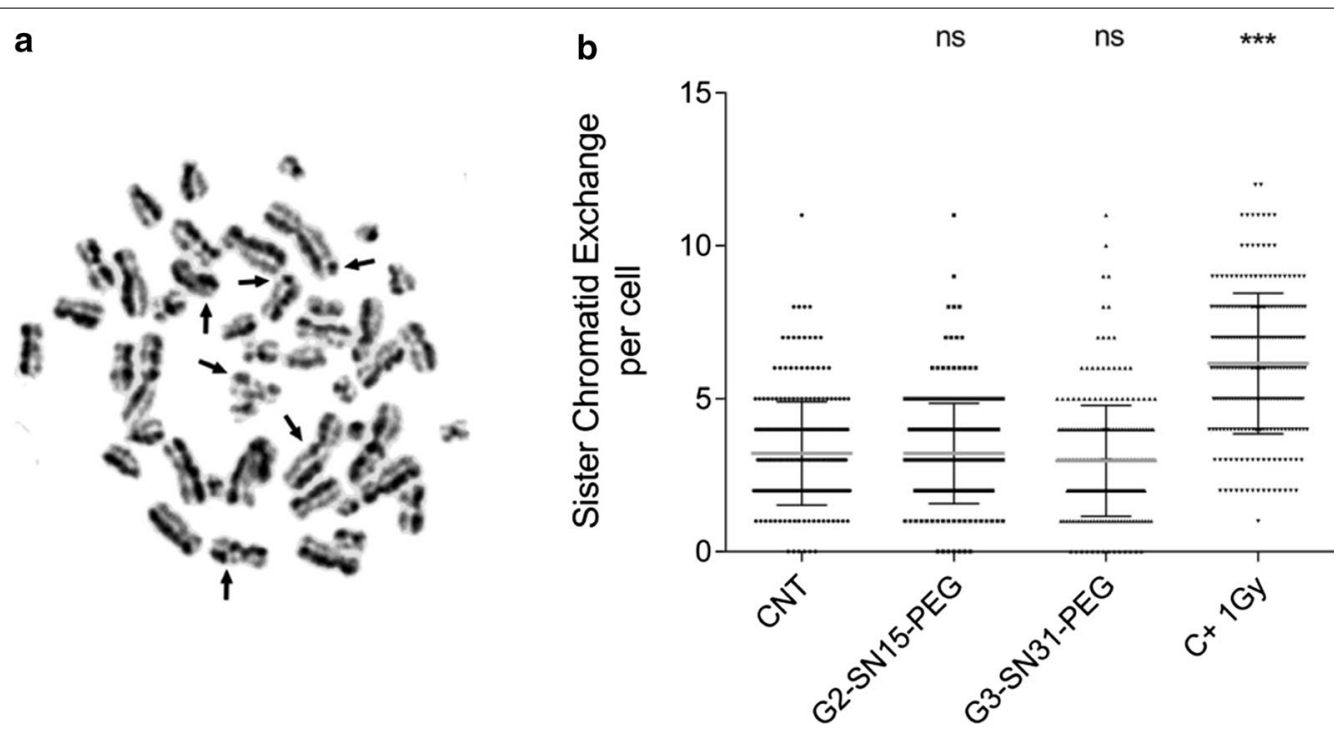

Fig. 2 Genotoxicity of carbosilane cationic dendrimers. Quantification of the number of sister-chromatid exchange per cell in PBMCs non-treated, PBMCs treated with G2-SN15-PEG $10 \mu \mathrm{M}$, G3-SN31-PEG $5 \mu \mathrm{M}$ or $1 \mathrm{~Gy}$ of radiation for $72 \mathrm{~h}$. a Images of random field obtained from the SCE assay after FPG staining. Arrows indicated the sister-chromatid exchange. $\mathbf{b}$ Analysis of the SCE assay. Data are represented as dot plots of five individual experiments (50 mitosis analysis per healthy donor). C+ 1 Gy 1 Gy radiation control, NT non-treated. $\left({ }^{*} p<0.05 ;{ }^{* *} p<0.01 ;{ }^{* * *} p<0.001\right)$

Table 1 Analysis of the genotoxicity of the dendrimers

\begin{tabular}{llcl}
\hline Treatment & SCE $($ mean \pm SD $)$ & P value & $\mathbf{n}$ \\
\hline CNT & $3.22 \pm 1.69$ & - & 250 \\
G2-SN-15-PEG & $3.22 \pm 1.65$ & 1.000 & 250 \\
G3-SN31-PEG & $2.98 \pm 1.82$ & 0.1272 & 250 \\
C+1 Gy & $6.15 \pm 2.29$ & $<0.0001$ & 250 \\
\hline
\end{tabular}

measuring the particle zeta potentials (ZP) and the particle size distribution by dynamic light scattering (DLS).

The positive values obtained from the study of the surface charge by ZP measurements confirmed the cationic density of the periphery of the nanoparticles. As shown in Table 2, G2-SN15-PEG dendrimer presents the highest potential value $(52,5 \mathrm{mV})$, which entails high electrical stability. For its part, G3-SN31-PEG presents a moderate value $(30,24 \mathrm{mV})$, which still represents good stability.

The formation of dendriplexes with hsa-miR-29a-3p led to a change in the $\mathrm{ZP}$ values of both dendrimers. More precisely, there is a decrease of the potential value when complexing G2-SN15-PEG dendrimer with the miRNA, whereas there is an increase of the value when forming the dendriplex from G3-SN31-PEG which suggests that the correct formation of the dendriplex took place.

Results obtained from the study of the particle size distribution by DLS (Table 3) suggest aggregation or self-assembly for G2-SN15-PEG (302,95 nm). On the contrary, much lower values were obtained for G3-SN31PEG dendrimer $(4,93 \mathrm{~nm})$ indicating that this one could be described as a single molecule. As for hsa-miR-29a-3p, its size was found with low aggregation degree $(14 \mathrm{~nm})$. In terms of dendriplexes formed with G2-SN15-PEG or G3-SN31-PEG dendrimers and hsa-miR-29a-3p, both presented moderate aggregation values (around 30 and $40 \mathrm{~nm}$, respectively). All these values supported with data obtained in electrophoresis assays, confirm the correct formation and stability of complexes.

\section{Internalization assay of the dendrimers}

The progressive entry of G2-SN15-PEG FITC and G3-SN31-PEG FITC dendrimers in PBMCs and U87MG$\mathrm{CD}^{+} \mathrm{CCR}^{+}$cell line was determined by confocal microscopy and flow cytometry. For confocal microscopy cells were treated with dendrimers, $(5$ and $1 \mu \mathrm{M}$ for PBMCs or 1 and $0.5 \mu \mathrm{M}$ for U87MG-CD $4^{+}$CCR $5^{+}$cell line), for $1 \mathrm{~h}, 2 \mathrm{~h}$ or $6 \mathrm{~h}$. Results show a notable difference in the uptake of both dendrimers in CD3 positive cells. In terms of G2-SN15-PEG FITC, there was no differences in the uptake among the studied times, after $1 \mathrm{~h}$ of incubation around $90 \%$ of PBMCs were positive for dendrimer presence inside the host cell and differences were not detected in the entry percentage at 1, 2 or $6 \mathrm{~h}$. Likewise, when PBMCs were treated with G3-SN31-PET FITC no differences in the uptake at different time points were detected. However, this G3-SN31-PEG FITC showed a percentage of positivity much lower than the previous dendrimer, only around $16 \%$ of positive cells (Fig. 5a, b).

U87MG-CD $4{ }^{+} \mathrm{CCR}^{+}$cells were treated with G2-SN15-PEG FITC $1 \mu \mathrm{M}$ or G3-SN31-PEG FITC 
a

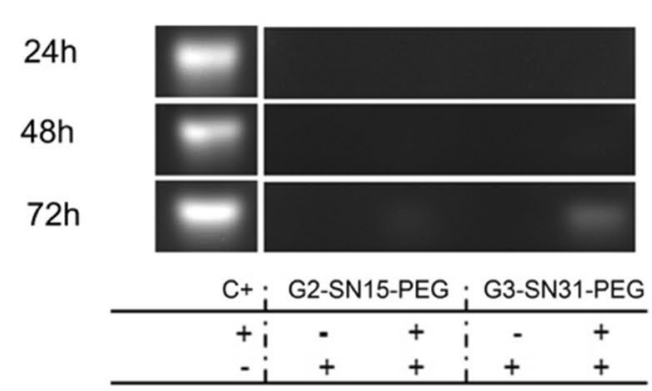

C

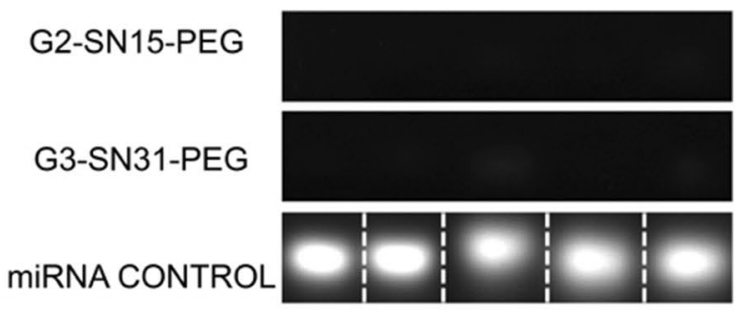

e
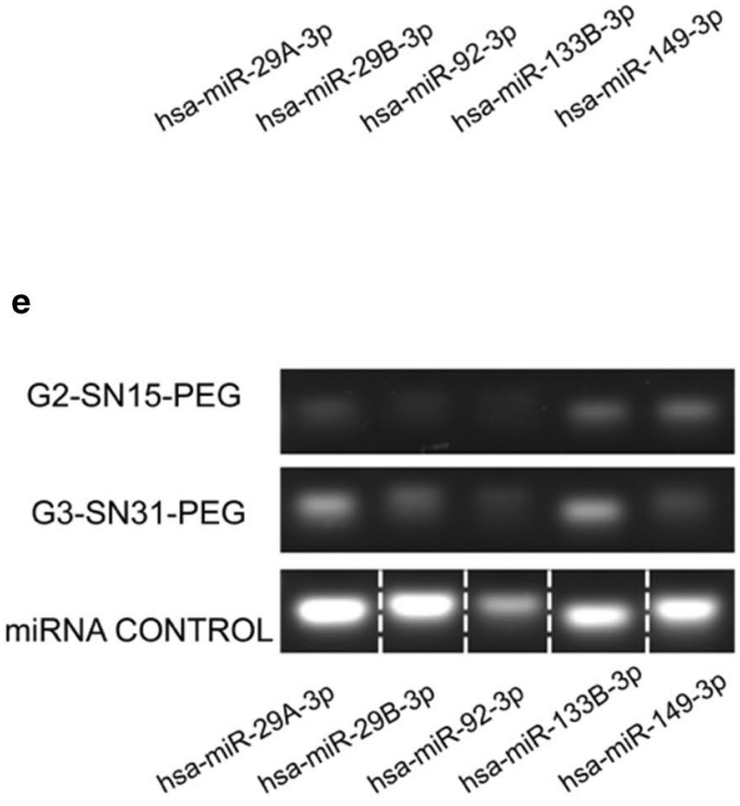

b

- G2-SN15-PEG $\triangle$ G3-SN31-PEG

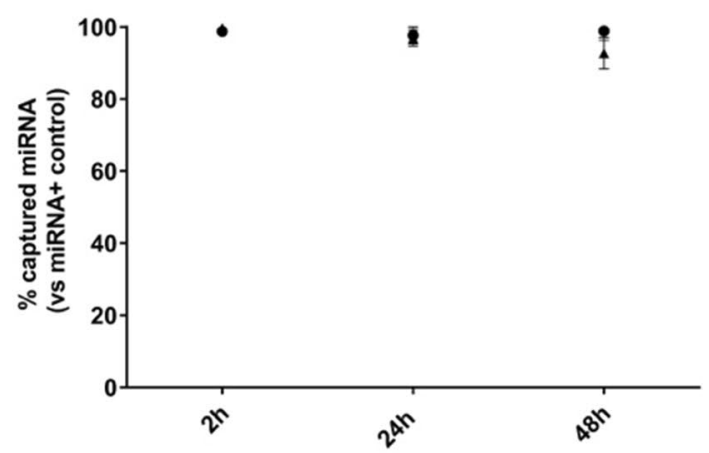

d

- G2-SN15-PEG ^ G3-SN31-PEG

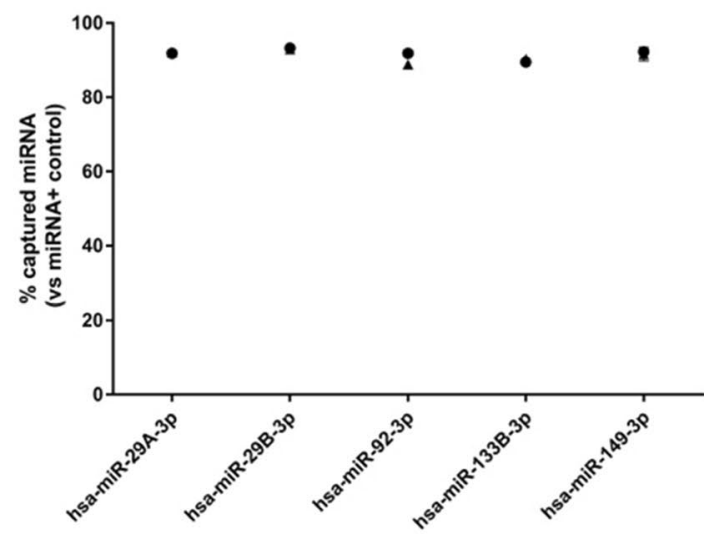

- G2-SN15-PEG \ G3-SN31-PEG

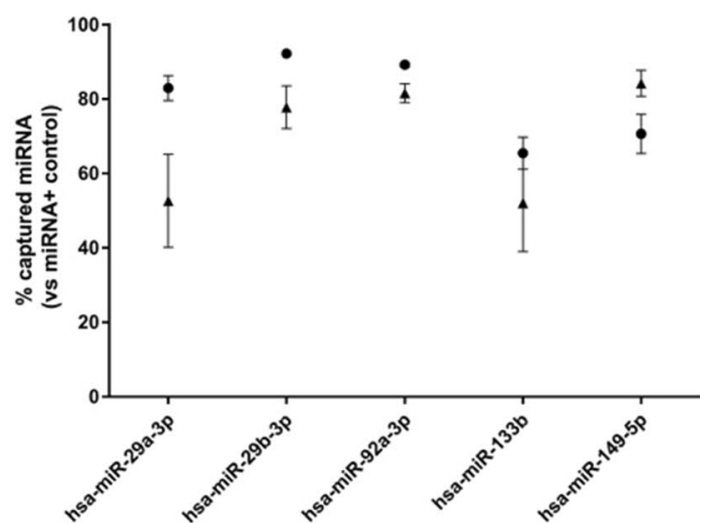

Fig. 3 Dendriplexes characterization. a Two per cent agarose gel electrophoresis showing the formation of different dendriplexes after $2 \mathrm{~h}, 24 \mathrm{~h}$ or $48 \mathrm{~h}$ of incubation of control microRNA with G2-SN15-PEG $10 \mu \mathrm{M}$ and G3-SN31-PEG $5 \mu \mathrm{M}$ dendrimers. b Percentage of microRNA captured vs. miRNA control after 2, 24 or $48 \mathrm{~h}$ of incubation. c Formation of dendriplexes with anti-HIV-1 microRNAs (hsa-miR-29a-3p, hsa-miR-29b-3p, hsa-miR-92a-3p, hsa-miR-133b and hsa-miR-149-5p) and G2-SN15-PEG (10 $\mu \mathrm{M})$ and G3-SN31-PEG $(5 \mu \mathrm{M})$ dendrimers after $2 \mathrm{~h}$ of incubation. d Percentage of microRNA captured vs. miRNA control after $2 \mathrm{~h}$ of incubation. e Formation of dendriplexes with anti-HIV-1 microRNAs and G2-SN15-PEG $(5 \mu \mathrm{M})$ and G3-SN31-PEG $(1 \mu \mathrm{M})$ dendrimers. f Percentage of microRNA captured vs. miRNA control 

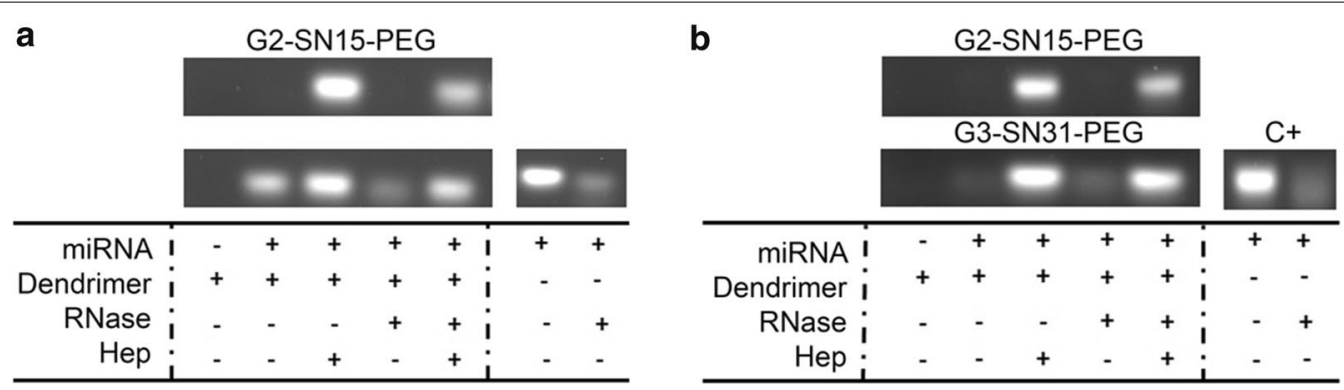

Fig. 4 Heparin competition and RNase protection assays. Dendriplexes were prepared with miRNA control $2 \mathrm{~h}$ before being treated with heparin and/or RNases. Dendrimers concentrations were a G2-SN15-PEG $10 \mu \mathrm{M}$ and G3-SN31-PEG $5 \mu$ M or b G2-SN15-PEG $5 \mu$ M and G3-SN31-PEG $1 \mu$ M

Table 2 ZP values ( $\mathrm{mV}$ ) for dendrimers and dendriplexes formed with G2-SN15-PEG and G3-SN31-PEG and hsa-miR-29a-3p

\begin{tabular}{ll}
\hline Compound & Zeta potential $(\mathbf{m V})$ \\
\hline G2-SN15-PEG & $52.5 \pm 0.42$ \\
G2-SN15-PEG + hsa-miR-29a-3p & $49.45 \pm 1.62$ \\
G3-SN31-PEG & $30.6 \pm 0$ \\
G3-SN31-PEG + hsa-miR-29a-3p & $32.24 \pm 2.37$ \\
\hline
\end{tabular}

Table 3 Measure of hydrodynamic size for dendrimers and dendriplexes formed with G2-SN15-PEG, G3-SN31-PEG and hsamiR-29a-3p

\begin{tabular}{lc}
\hline Compound & $\begin{array}{l}\text { Hydrodynamic } \\
\text { size (diameter, } \\
\mathbf{n m} \text { ) }\end{array}$ \\
\hline G2-SN15-PEG & $302.95 \pm 14.78$ \\
G2-SN15-PEG + hsa-miR-29a-3p & $30.19 \pm 2.88$ \\
G3-SN31-PEG & $4.93 \pm 0.26$ \\
G3-SN31-PEG + hsa-miR-29a-3p & $41.1 \pm 2.88$ \\
hsa-miR-29a-3p & $14.42 \pm 4.16$ \\
\hline
\end{tabular}

$0.5 \mu \mathrm{M}$ and the internalization was again studied by confocal microscopy (Fig. 6a) and flow cytometry (Fig. 6b). In this case we can observe again a differential entry between G2-SN15-PEG FITC and G3-SN31-PEG FITC dendrimers and an increase in the number of positive cells along the selected time points. After $1 \mathrm{~h}$ of incubation, both dendrimers were found in the outside part of the cell membrane, due to the fact that both dendrimers co-localize with F-actin and flow cytometry indicated that $40 \%$ of cells were positive for G2-SN15PEG FITC whereas only $20 \%$ of cells where positive for G3-SN31-PEG FITC. However, after $2 \mathrm{~h}$ of incubation we observed a notable increase inside cells and positivity values raised to 50 and $45 \%$, respectively, suggesting that both dendrimers need at least $2 \mathrm{~h}$ for internalize into U87MG-CD4 $4^{+} \mathrm{CCR} 5^{+}$cells.

Our results indicate that both G2-SN15-PEG FITC and G3-SN31-PEG FITC dendrimers are capable of entering inside of PBMCs and U87MG-CD $4{ }^{+} \mathrm{CCR} 5^{+}$cells in less than $6 \mathrm{~h}$, showing that both dendrimers could be used as delivery systems.

\section{HIV-1 inhibition activity of the dendriplexes}

To determine the anti-HIV-1 activity of dendriplexes, inhibition experiments were performed using nonlabelled dendrimers, with the objective that these dendrimers could be used as a possible therapy. PBMCs or U87MG-CD $4^{+} \mathrm{CCR}^{+}$cells were infected with R5-HIV$1 \mathrm{NL}_{(\mathrm{AD} 8)}$ and treated with dendriplexes after $2 \mathrm{~h}$ of incubation of G2-SN15-PEG or G3-SN31-PEG dendrimer and the anti-HIV-1 miRNAs at concentrations of 10 and $5 \mu \mathrm{M}$ for PBMCs or 5 and $1 \mu \mathrm{M}$ for U87MG-CD $4^{+} \mathrm{CCR} 5^{+}$, respectively. Then, $72 \mathrm{~h}$ after $\mathrm{R} 5-\mathrm{HIV}-1 \mathrm{NL}_{(\mathrm{AD} 8)}$ infection, supernatants of PBMCs or U87MG-CD4 ${ }^{+} \mathrm{CCR} 5^{+}$cells were collected and titrated on TZM.bl cells to quantify

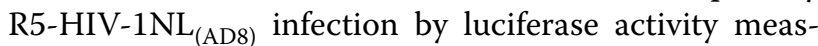
urements. Non-treated samples were used as uninfected control. The treatment of PBMCs with G2-SN15-PEG or G3-SN31-PEG dendrimer caused around 80 or $45 \%$ of HIV-1 reduction, regarding the control of infection. This inhibition was even greater when PBMCs were treated with dendriplexes formed with anti-HIV-1 miRNAs and both G2-SN15-PEG or G3-SN31-PEG dendrimer showing a significant increase of inhibition reaching values of 96 and $73 \%$ reduction of HIV-1 infection, respectively (Fig. 7a).

Treatment of U87MG-CD $4^{+}$CCR $5^{+}$cells (Fig. 7b) with G2-SN15-PEG FITC $1 \mu \mathrm{M}$ or G3-SN31-PEG dendrimer caused a significant inhibition of HIV-1 infection, around $40 \%$, in agreement with previously mentioned in the bibliography.34 Moreover, the treatment with some of the dendriplexes produced an increase of HIV-1 inhibition, for example 


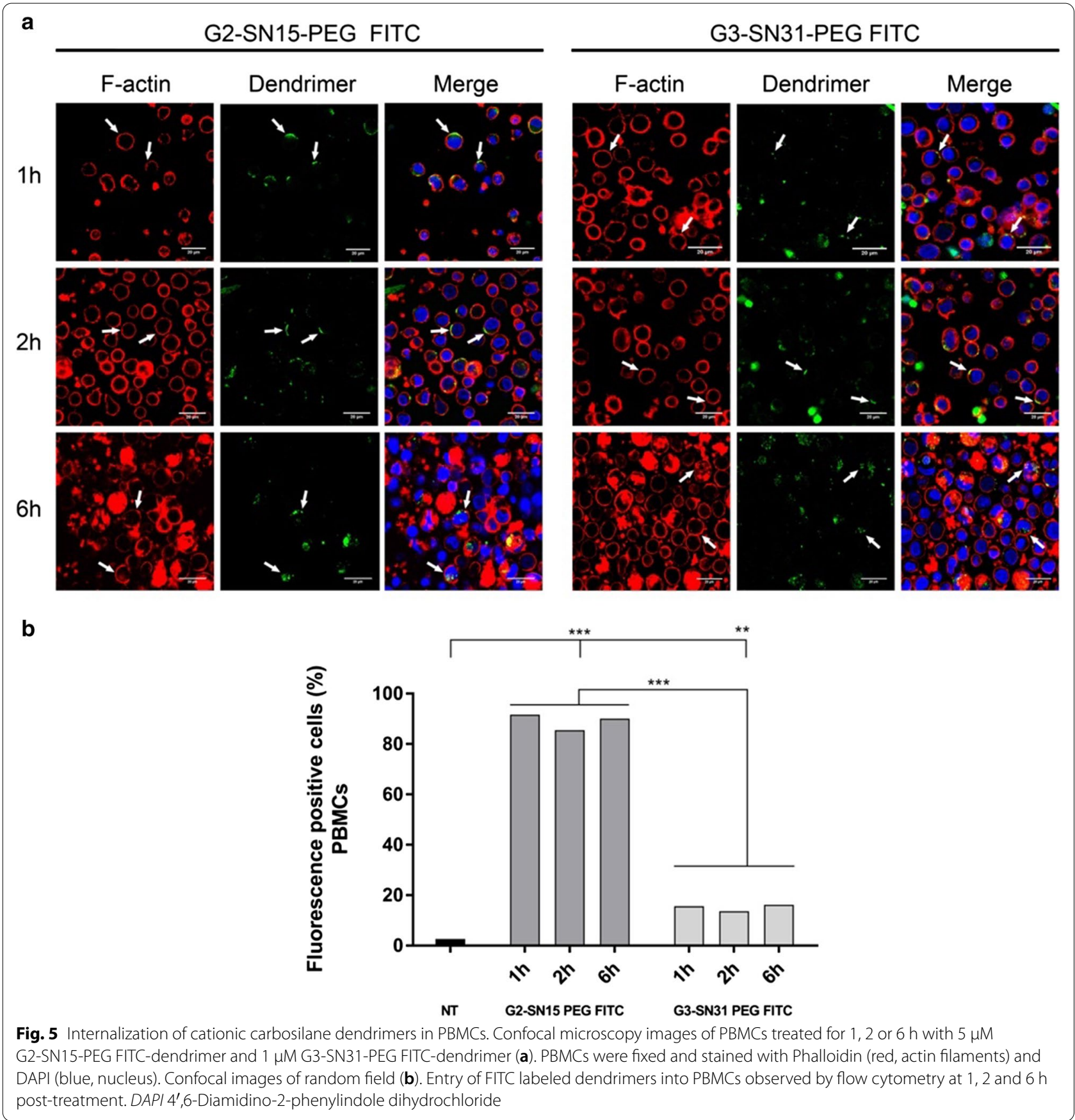

hsa-miR-29A-3p with G2-SN15-PEG or G3-SN31-PEG dendrimer. As expected, this increase was not significant regarding the inhibition resulting from the treatment with only G2-SN15-PEG or G3-SN31-PEG dendrimer, suggesting that dendriplexes cause a significant inhibition of R5-HIV-1 infection only in specific cell lines.

\section{Discussion}

Combinations of antiretroviral therapies have been a major step towards controlling HIV-1 infection, suppressing viral load to undetectable levels, and reducing mortality and morbidity associated with HIV-1 infection $[38,39]$. These treatments are unable to overcome the main problems that infection still entails: the existence of 


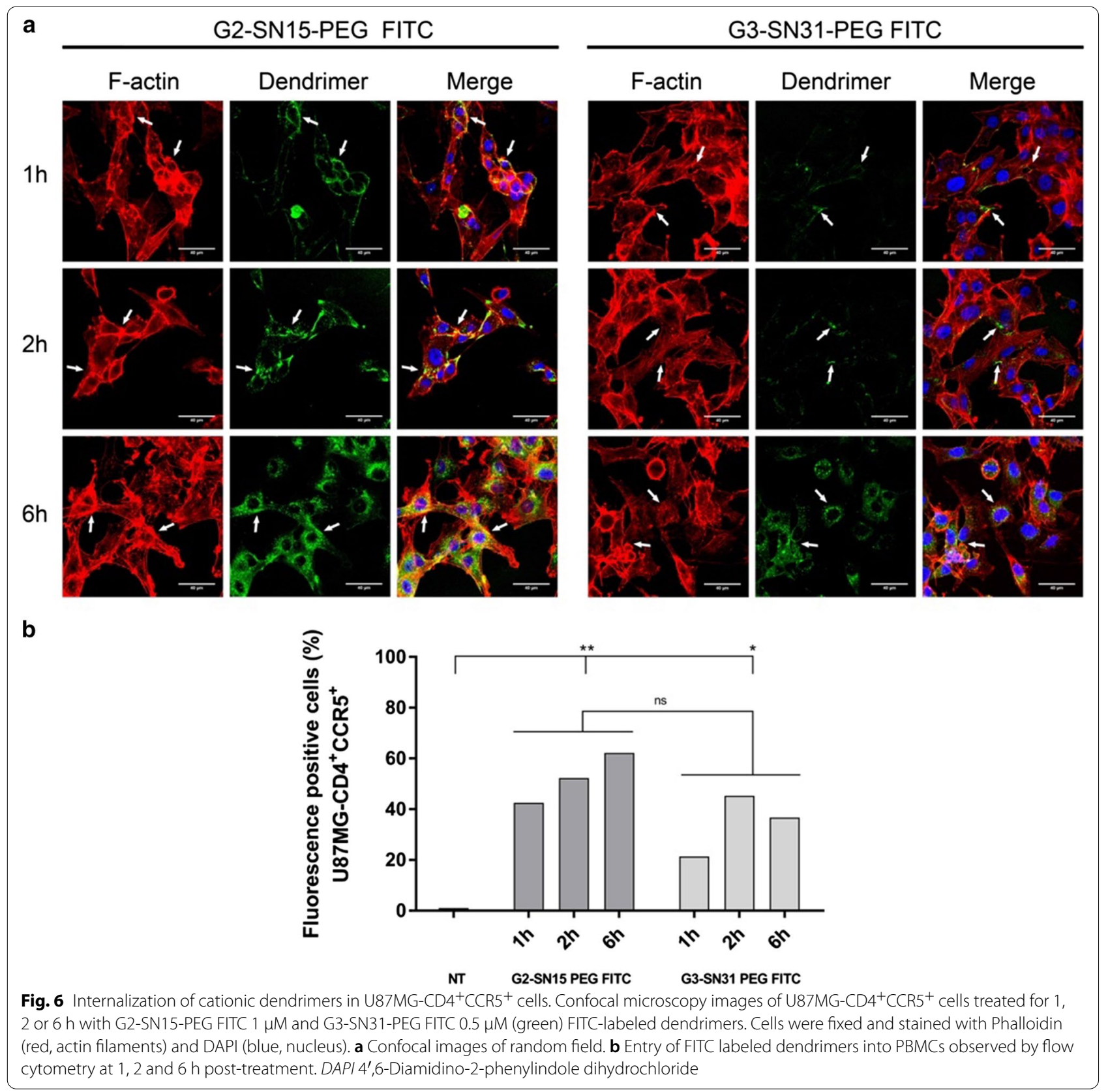

stable viral reservoirs and appearance of resistant strains [40-43]. The use of small RNAs is a powerful approach to target these problems, since a broad range of miRNAs has a negative impact on HIV-1 replication [28-30]. The delivery of miRNAs to infected cells constitutes a boundary for its efficient application. Nanotechnology is a strategy to address this issue, since it has previously shown to efficiently deliver small RNA molecules or small miRNAs [12-14]. Our group has carried out wide research about this topic, specifically related to the use of dendrimers in the context of HIV-1 infection [18, 23, 44, 45]. These three-dimensional hyperbranched nanostructures have modifiable edges which promote, for example, the formation of dendriplexes through the interplay among these edges, when positively charged, and the negatively charged backbone of small RNAs. We have analyzed the potential therapeutic effect of the use of four novel cationic dendrimers as delivery systems for different antiHIV-1 miRNAs to control HIV-1 progression in PBMCs and U87MG-CD4 ${ }^{+}$CCR $5^{+}$cells.

The initial phase of this study was to determine the biocompatibility of dendrimers on PBMCs and 
a

$* * *$

$\star \star \star *$

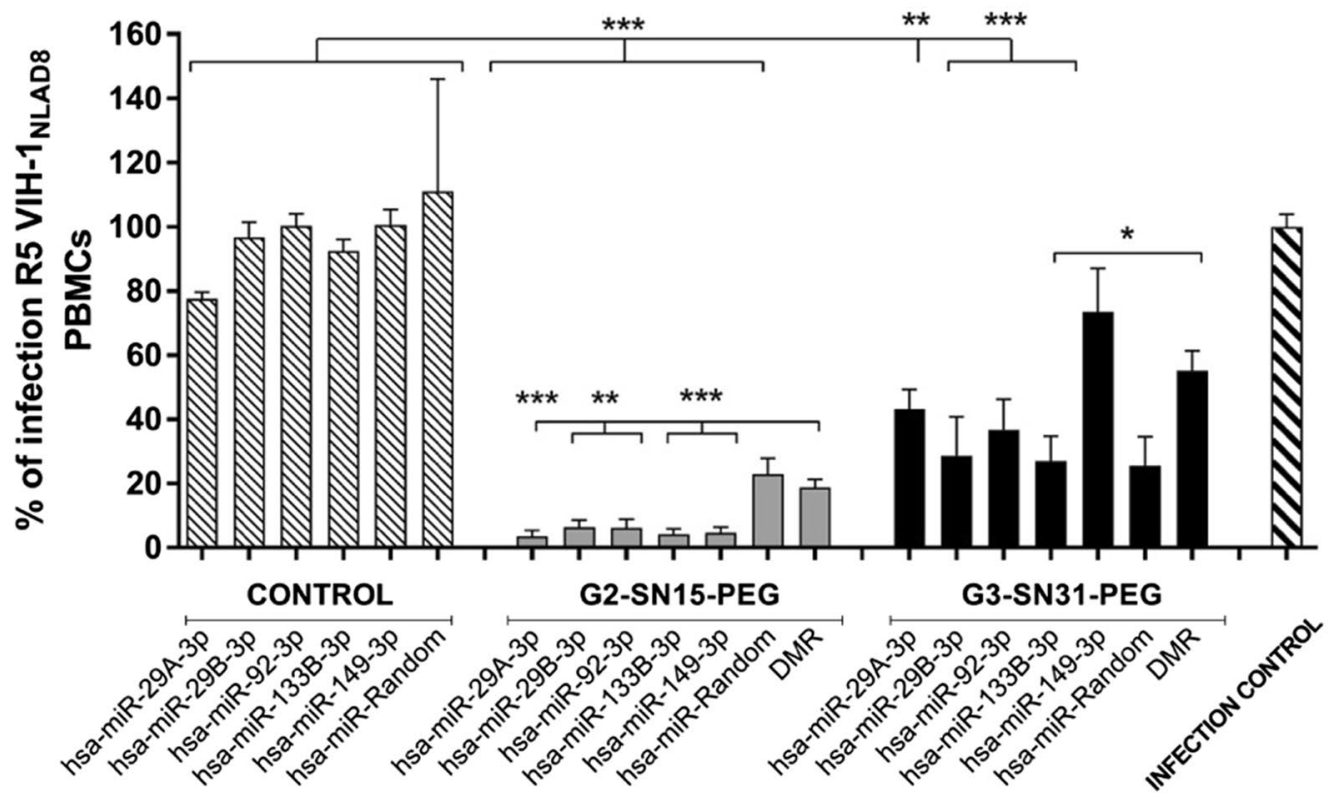

b
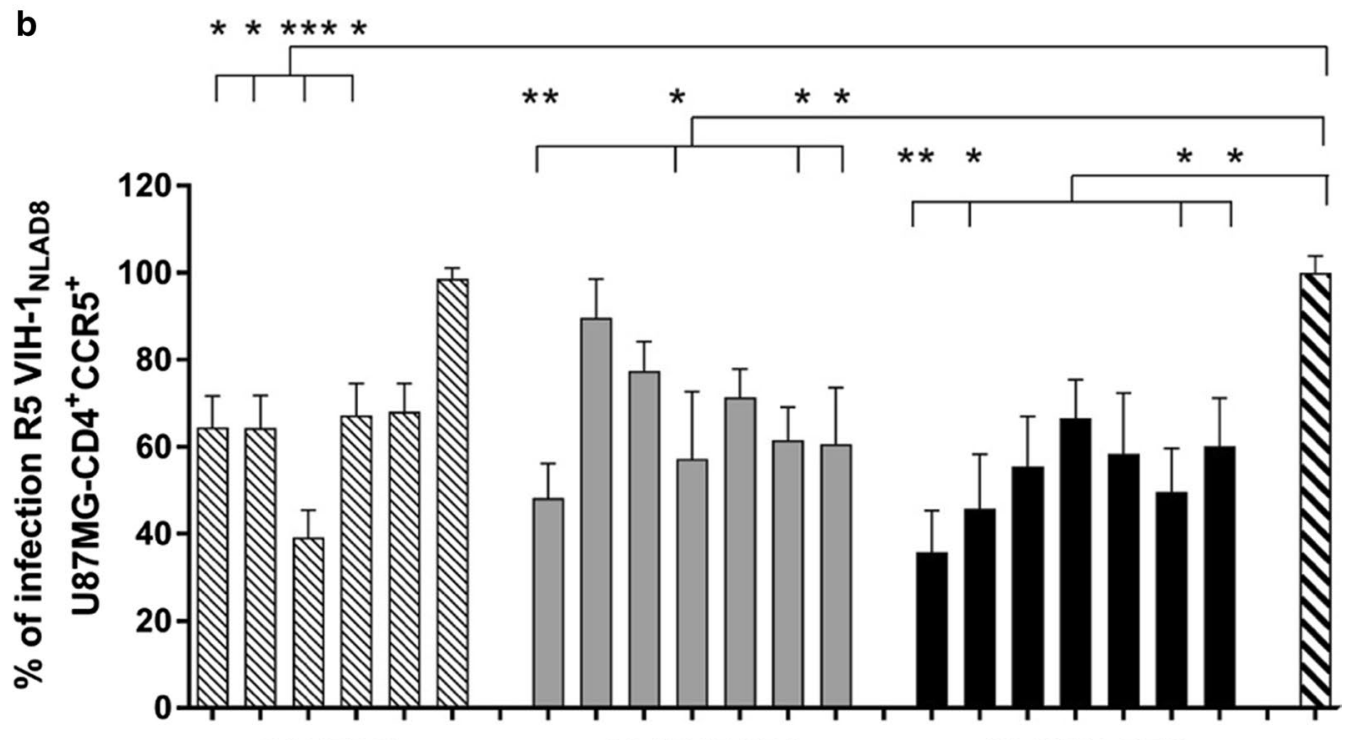

120

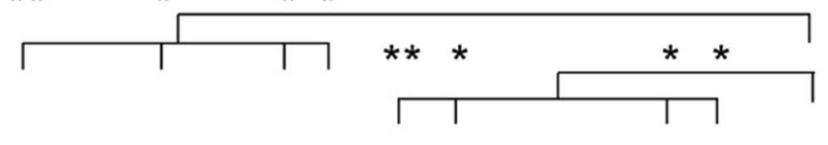

CONTROL

G2-SN15-PEG

G3-SN31-PEG

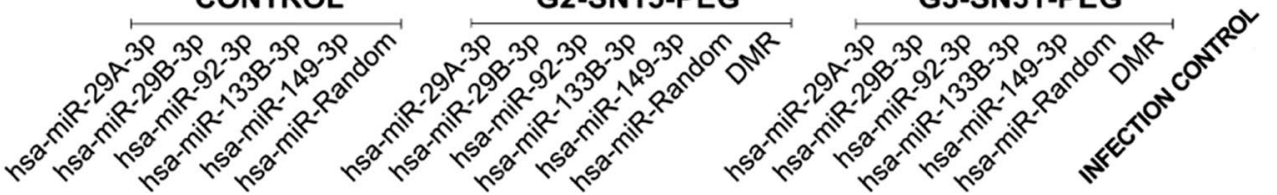

Fig. 7 HIV-1 inhibition of dendriplexes. Quantification of R5-HIV-1 infection in a PBMCs and $\mathbf{b}$ U87MG-CD4 ${ }^{+}$CCR5 ${ }^{+}$cells treated with dendriplexes. Infection was measured by titration of supernatants on TZM.bl cell line. Infection was inferred from the measurement of luciferase activity $48 \mathrm{~h}$ post-titration and was represented as fold change of percentage from HIV-1 infection control. Dendriplexes were formed with non-labeled G2-SN15-PEG or G3-SN31-PEG cationic dendrimer and control or anti-HIV-1 microRNAs (hsa-miR-29a-3p, hsa-miR-29b-3p, hsa-miR-92a-3p, hsa-miR-133b and hsa-miR-149-5p). Data are represented as mean \pm SD of three individual experiments performed in triplicate. DMR: dendrimer. $\left({ }^{*} p<0.05 ;{ }^{* *} p<0.01 ;{ }^{* * *} p<0.001\right)$ 
U87MG-CD $4{ }^{+} \mathrm{CCR} 5^{+}$cell line. Cationic dendrimers interact with cell surface, which is negatively charged, producing nanoscale pores in the membrane increasing its permeability. This interaction affects the integrity of membrane depending on different characteristics of dendrimers, such as molecular size or presence of fluorescent markers that could lead to cell death [46]. Therefore, our four dendrimers were conjugated with PEG to mask some cationic groups reducing the toxicity and immunogenicity, and improving solubility, drug loading and drug delivery [32].

Cytotoxicity analysis, performed by MTT assay showed that G3-SN31-PEG FITC dendrimer had the highest toxicity rates followed by G2-SN15-PEG FITC, G3-SN31PEG and G2-SN15-PEG dendrimers, respectively. As expected, our results show that larger molecular sizes and introduction of fluorescent labels enhance the cytotoxicity of compounds. Studies of genotoxicity, based on SCE assay, showed that non-labelled dendrimers can be used in vivo, did not cause genetic toxicity. It is important to note that these dendrimers could be not used if they affect the host genome and produced genetic changes. The fact that selected miRNAs are naturally present on host cell makes unnecessary to study genotoxicity of these dendrimers.

The capability of different PEGylated cationic dendrimers to complex with various miRNAs to form dendriplexes using the maximum non-toxic working concentrations was studied. Dendriplexes were formed by electrostatic interactions among positively charged functional groups at periphery of dendrimers and negatively charged backbone of small miRNAs [47]. G2-SN15-PEG and G3-SN31-PEG dendrimers can efficiently form dendriplexes after $2 \mathrm{~h}$ of incubation with different miRNA in agarose gel electrophoresis.

We also analyzed whether dendrimers conferred protection to miRNAs from RNase-mediated degradation and if dendrimer-miRNA bound could be disengaged in order to enable its binding mRNA. RNase protection assay showed that miRNAs are completely recovered from dendriplex after incubation with RNases, indicating that dendrimer-miRNA complex protects miRNAs from degradation. Moreover, dendriplexes can be completely dissociated when dealing with a binding site competitor, such as heparin. Moreover, dendrimer-miRNAs complex will act in case of piercing of plasmatic membrane of host cell, because heparin assay recreates this situation caused by the disparity in the number of charges due to different environments between cytoplasm and extracellular fluids, thus proving that dendrimers release complexed miRNA when internalizing in the host cell.

To evaluate how the addition of the miRNAs affects the properties of the dendrimer we studied the surface charge and stability by measuring the particle zeta potentials (ZP) and the particle size distribution by dynamic light scattering (DLS). Results indicated that both dendrimers are stable, and their surface charges are positive in solution. In addition, results showed a fall of the ZP value in third-generation dendrimer (G3-SN31-PEG) compared to second-generation dendrimer (G2-SN15-PEG), which can be explained on the basis of a more effective wrapping of the PEG moiety, because PEGylation reduces charge density, as previously described elsewhere [48]. When studying the effect of the complexation of miRNAs, values showed a small change of ZP values, confirming the formation of the dendriplexes without affecting the stability of the particles.

In terms of the particle size distribution, G2-SN15-PEG dendrimer was found to form aggregates probably due to a reorganization over time owing to interactions between different molecules when it is in solution. On the other hand, G3-SN31-PEG dendrimer was described as a single molecule and hsa-miR-29a-3p also presented low aggregation values. It would be expected for the hydrodynamic size of the complexes to be superior to that of the individual dendrimers as discrete particles. However, when forming the dendriplex with G2-SN15-PEG dendrimer aggregation values were lower, which could be explained because the introduction of the miRNA into the medium leads to more favorable electrostatic binding and contributes to more stable systems in solution without the need for aggregation by the dendrimer. The nanoconjugate formed with G3-SN31-PEG dendrimer and hsa-miR29a-3p presented the expected increase in the hydrodynamic size after the formation of the complex. Changes in particle size distribution of the dendrimers, along with data obtained in electrophoresis assays, confirm the correct formation and stability of complexes.

The internalization of both FITC-labelled dendrimers in PBMCs and U87MG-CD4 ${ }^{+} \mathrm{CCR} 5^{+}$cells confirm that these dendrimers could be used as carriers. Cationic dendrimers cross cell membranes with different effectiveness depending on dendrimer properties such as size or surface charge and cellular features such as and membrane chemical composition. These elements determine the affinity with which dendrimers are bound to cell surface: higher amounts of positive charges entail stronger interactions that lead to longer resident times on membrane and, thus, slower internalization [49]. This fact has been reflected in our results, where we can observe a higher internalization of G2-SN15-PEG FITC dendrimer in both cell lines studied compared to G3-SN15-PEG FITC dendrimer, probably due to a higher affinity with cell surface produced by the presence of more positive charges being a bigger molecule. 
Regardless of this result, both dendrimers are able to internalize into host cells in less than $6 \mathrm{~h}$ and these two dendrimers present a resembling behavior inside the cells, showing that both dendrimers can be used as delivery systems.

After demonstrating that G3-SN31-PEG FITC and G2-SN15-PEG FITC dendrimers form stable dendriplexes that confer protection to different miRNAs and that can be efficiently delivered, we studied their antiHIV-1 activities. This activity was tested in R5-HIV$1 \mathrm{NL}_{(\mathrm{AD} 8)}$ infected PBMCs and U87MG-CD4 ${ }^{+} \mathrm{CCR} 5^{+}$ cells to determine whether the conjugation of both G3-SN31-PEG and G2-SN15-PEG non-labelled dendrimers with cellular anti-HIV-1 miRNAs improved the therapeutic effect. Our results showed that both dendrimers are able to significantly inhibit HIV-1 infection in both PBMCs and U87MG-CD4 + CCR5 cells. However, inhibition with dendriplexes was only significantly improved when treating PBMCs suggesting a specific behavior depending on cell lineage. The selected miRNAs cannot decrease the HIV-1 infection by themselves in PBMCs. They need the formation of complexes with dendrimers. The main objective was to prove that these novel cationic dendrimers can be used as delivery agents in order to replace current methods and develop a safer method with possible in vivo perspectives. Our results could fill the gap between the in vitro delivery researches and the possibility of implementing this technology in clinic, developing a new "from bench to patient" safe and effective technology.

\section{Conclusion}

In conclusion, the PEGylated carbosilane dendrimers G2-SN15-PEG and G3-SN31-PEG are valid delivery systems for miRNAs. Formation of dendriplexes provides miRNAs with protection against degradation and enables delivery to different cells. These dendriplexes specifically and significantly improve the anti-R5-HIV-1 activity of miRNAs, being good candidates to be used therapeutically to address the main problems that the HIV-1 infection still entails.

\section{Methods}

\section{Cell lines}

TZM.bl cell line (NIH AIDS Research and Reference Reagent Program, Germantown, MD, USA) is a human cervical epithelial carcinoma cell (HeLa cell line), that expresses CD4 receptor and CCR5 co-receptor and contains $\beta$-galactosidase and luciferase genes under control of long terminal repeat (LTR) regions of HIV-1 promoter [50]. U87MG-CD4 ${ }^{+} \mathrm{CCR}^{+}$(NIH AIDS Research and Reference Reagent Program, Germantown, MD, USA) is a human astrocytoma (glioblastoma) cell line derived from U87MG to express CD4 receptor and CCR5 and CXCR4 co-receptors.

TZM-bl cell line was cultured in Dulbecco's Modified Eagle's Medium (DMEM) (Biochrom GmbH, Berlin, Germany) supplemented with $5 \%$ heat-inactivated fetal bovine serum (FBS) (Biochrom GmbH, Berlin, Germany), $2 \mathrm{mM}$ L-glutamine (Lonza, Base, Switzerland) and a cocktail of antibiotics $(125 \mathrm{mg} / \mathrm{ml}$ ampicillin, $125 \mathrm{mg} / \mathrm{ml}$ cloxacillin and $40 \mathrm{mg} / \mathrm{ml}$ gentamicin (Normon, Madrid, Spain) $)$ at $37^{\circ} \mathrm{C}$ with $5 \% \mathrm{CO} 2 . \mathrm{U} 87 \mathrm{MG}-\mathrm{CD} 4^{+} \mathrm{CCR} 5^{+}$cell line was maintained in DMEM supplemented with $10 \%$ FBS, $2 \mathrm{mM}$ L-glutamine and the aforementioned antibiotic cocktail at $37^{\circ} \mathrm{C}$ with $5 \% \mathrm{CO} 2$.

\section{Primary cells}

Buffy coats, acquired from healthy anonymous donors from the Transfusion Centre of Madrid (Madrid, Spain) following the current legislation, were used to obtain PBMCs on a Ficoll-Hypaque density gradient (Rafer) according to standard procedures of Spanish HIV HGM BioBank [51].

After the isolation, PBMCs were cultured $\left(5 \times 10^{6} / \mathrm{mL}\right)$ in RPMI 1640 (Biochrom GmbH, Berlin, Germany) supplemented with 10\% FBS, $2 \mathrm{mM}$ L-glutamine, the aforesaid cocktail of antibiotics, $60 \mathrm{IU} / \mathrm{mL}$ of interleukin-2 (IL-2, Bachem, Budendorf, Switzerland) and $2 \mu \mathrm{g} / \mathrm{mL}$ of phytohemagglutinin (PHA) (Remel, Dartford, Kent, UK).

\section{Viral isolates}

Viral stock of CCR5-tropic R5-HIV-1NL (AD8) $_{\text {labora- }}$ tory isolate was obtained by transient transfection with $\mathrm{pNL}_{(\mathrm{AD} 8)}$ plasmid (NIH AIDS Research and Reference Reagent Program, Germantown, MD, USA) into HEK293 T cell line (ATCC, Manassas, VA, USA). Viral stock was clarified by centrifugation and the viral titter was later evaluated using an HIV-1 p24gag enzyme-linked Immunosorbent assay (ELISA) kit (INNOTEST HIV, Antigen mAb, Innogenetics, Ghent, Belgium), as previously reported [52].

\section{MicroRNAs}

Five cellular miRNAs reported to have anti-HIV-1 activity were selected based on their homology with HIV-1 genome: hsa-miR-29a-3p, hsa-miR-29b-3p, hsa-miR92a-3p, hsa-miR-133b and hsa-miR-149-5p (QUIAGEN, Hilden, Germany) [33, 34]. We also selected one miRNA with random sequence but similar length and no activity against HIV-1 as a negative control (QUIAGEN, Hilden, Germany). Sequence, HIV-1 genome target and effect on HIV-1 replication are shown in Table 4. Stock solutions of miRNAs $(66,7 \mu \mathrm{M})$ and working concentrations (6670 nM) were prepared in nuclease-free water (Promega, Madrid Spain) and stored at $-20^{\circ} \mathrm{C}$. 
Table 4 Sequence, HIV-1 target and effect on HIV-1 replication of selected anti-HIV-1 microRNAs and control microRNA

\begin{tabular}{llll}
\hline Name & Sequence & HIV-1 genome target & $\begin{array}{c}\text { Effect } \\
\text { on HIV-1 } \\
\text { replication }\end{array}$ \\
\hline miR-29a-3p & UAGCACCAUCUGAAAUCGGUUA & Nef/3'UTR & Negative \\
miR-29b-3p & UAGCACCAUUUGAAUCAGUGUU & Nef/3'UTR & Negative \\
miR-92a-3p & UAUUGCACUUGUCCCGGCCUGU & Pol & Negative \\
miR-133b & UUUGGUCCCCUUCAACCAGCUA & Env & Negative \\
miR-149-5p & UCUGGCUCCGUGUCUUCACUCCC & Gag & Negative \\
miR-Control & UCACCGGUGUAAUCAGCUUG & - & None \\
\hline
\end{tabular}

\section{Dendrimers and reagents}

PEGylated cationic dendrimers G2-SN15-PEG and G3-SN31-PEG and their FITC-labelled forms were synthesized and tested according to the methods described by Dendrimers for Biomedical Applications Group of
University of Alcalá (Madrid, Spain). Stock solutions of dendrimers $(1 \mathrm{mM})$ and subsequent dilutions for working concentrations were prepared in nuclease-free water (Promega, Madrid Spain). The schematic structures of PEGylated cationic carbosilane dendrimers are represented in Fig. 8.

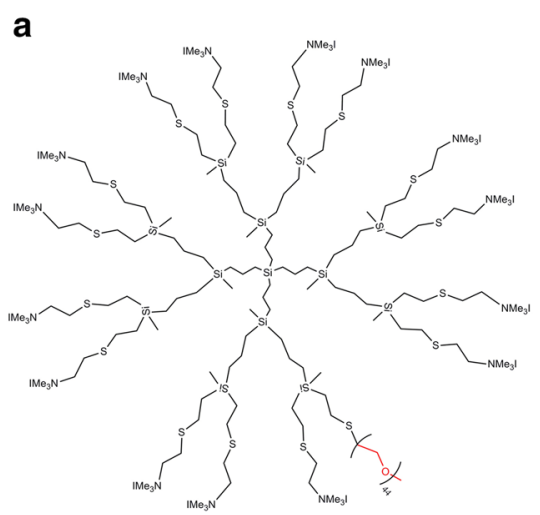

G2-SN15-PEG

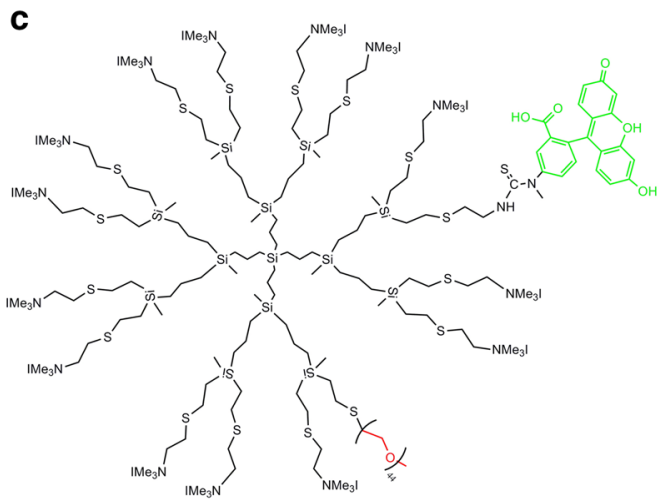

G2-SN15-PEG FITC b

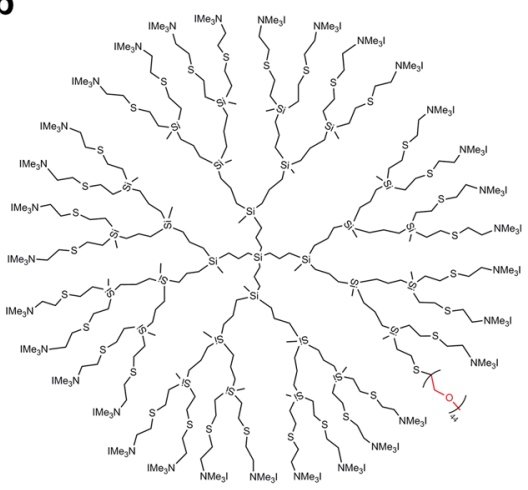

G3-SN31-PEG

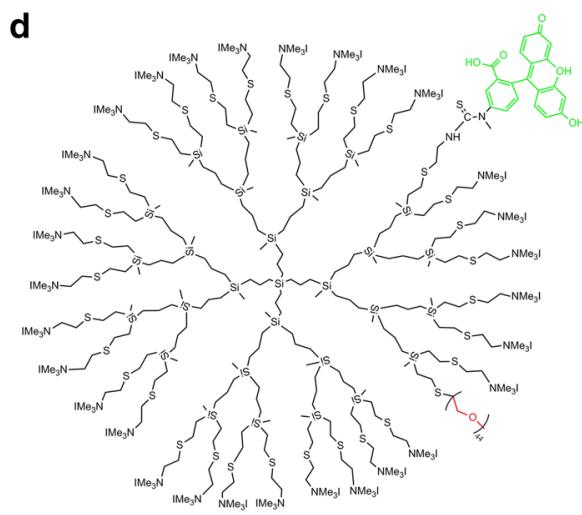

G3-SN31-PEG FITC

Fig. 8 Schematic representation of PEGylated cationic dendrimers. Molecular representation of a G2-SN15-PEG, c G2-SN15-PEG FITC (second generation dendrimers), b G3-SN15-PEG and d G3-SN31-PEG FITC (third generation dendrimers) 


\section{Mitochondrial activity assay}

Mitochondrial activity was determined by the 3-(4-5-dimethylthiazol-2-yl)-2,5-diphenyltetrazolium bromide (MTT) assay (Sigma, St Louis, MO, USA) following manufacturer's instructions to establish the mitochondrial toxicity of the dendrimers. Briefly, $2 \times 10^{5}$ PBMCs or $7.5 \times 10^{3}$ U87MG-CD $4^{+} \mathrm{CCR}^{+}$cells/well were seeded in 96-well plates and treated with different concentrations of dendrimers for $72 \mathrm{~h}$. After incubation, culture medium was discarded and a $200 \mu \mathrm{L}$ of a mixture of MTT/Opti-MEMTM solution (1:11) (Thermo Fisher Scientific, Waltham, MA, USA) was added. After $2 \mathrm{~h}$, the reaction was stopped by removing the solution and dissolving the formazan crystals in $200 \mu \mathrm{L}$ of dimethyl sulfoxide (DMSO, Honeywell, Charlotte, NC, USA) and absorbance was recorded in a Synergy 4 plate reader (BioTek, Winooski, VT, USA) at $490 \mathrm{~nm}$. Ten per cent DMSO was used as cellular death control and culture medium as non-treated control. All measurements were performed in triplicate three times.

\section{Genotoxicity of dendrimers}

To assess the genotoxicity of non-labelled G2-SN15PEG and G3-SN31-PEG dendrimers sister chromatids exchange (SCE) assay was performed in PBMCs. Cells were treated with G2-SN15-PEG $10 \mu \mathrm{M}$ or G3-SN31PEG $5 \mu \mathrm{M}$ for $72 \mathrm{~h}$. Radiation at $1 \mathrm{~Gy}$ was used as genotoxic positive control and non-treated cells were used as control of genetic viability. Cell cultures were then treated with $25 \mu \mathrm{M}$ bromodeoxyuridine (BrdU) (Thermo Fisher Scientific, Waltham, MA, USA) to monitor second divisions. After $70 \mathrm{~h}, 0.1 \mu \mathrm{M} / \mathrm{mL}$ colcemid (Thermo Fisher Scientific, Waltham, MA, USA), a mitosis inhibitor, was added to cultures and, $2 \mathrm{~h}$ after, metaphases were extended and analyzed by fluorescence plus Giemsa (FPG). Briefly, cells were centrifuged $10 \mathrm{~min}$ at $600 \mathrm{~g}$ and the supernatant was discarded and $10 \mathrm{~mL}$ of $5.6 \mu \mathrm{g} / \mathrm{mL}$ potassium chloride (Merck KGaA, Darmstadt, Germany) was added. Cells were then centrifuged $10 \mathrm{~min}$ at $600 \mathrm{~g}$, the supernatant was discarded, and the pellet was fixed with methanol/glacial acetic acid (3:1) (PanReac AppliChem, Madrid, Spain). This procedure was repeated 3 more times and the resulting metaphases were dropped over slides (Thermo Fisher Scientific, Waltham, MA, USA).

After $48 \mathrm{~h}$ maturing at $56^{\circ} \mathrm{C}$, slides were immersed in Hoechst solution (Sigma, St Louis, MO, USA) for $30 \mathrm{~min}$, washed with water and immersed in Mcllvaine buffer ( $0.55 \mathrm{~mL}$ citric acid plus $19.45 \mathrm{~mL}$ di-Sodium hydrogen phosphate) (Merck KGaA, Darmstadt, Germany), for $40 \mathrm{~min}$ in a thermostatic plate at $56^{\circ} \mathrm{C} 5 \mathrm{~cm}$ away from UV light. Slides were then washed and stained with Giemsa (Merck KGaA, Darmstadt, Germany) for $7 \mathrm{~min}$.
Images were obtained with a Leica DM 5000 B Microscope and analyzed with Cytovision ${ }^{\circledR}$ software (Leica, Wetzlar, Germany).

\section{Dendriplexes formation}

Dendrimer-miRNA complexes were formed mixing the maximum non-toxic concentration of the different cationic dendrimers with $100 \mathrm{nM}$ of the desired miRNAs in nuclease-free water (Promega, Madrid, Spain). The formation and stability of dendriplexes were evaluated by agarose gel electrophoresis after 2, 24 and $48 \mathrm{~h}$ of incubation at room temperature (RT). Samples were treated with Blue/Orange Loading Dye 6X (Promega, Madrid, Spain) and loaded on a gel with $2 \%$ agarose (Sigma, St Louis, MO, USA) and 0.01\% GelRed ${ }^{\circledR}$ (Biotium, Fremont, CA, USA) in Tris-acetate-EDTA (TAE) buffer (PanReac AppliChem, Darmstadt, Germany) at $120 \mathrm{mV}$ for $40 \mathrm{~min}$ on a PowerPac Universal power supply (Bio-Rad Laboratories, Hercules, CA, USA).

\section{Heparin competition assay and RNase protection}

Heparin exclusion and RNase protection assays were performed to test the capacity to disengage miRNAs from the complex and whether the formation of dendriplexes confers protection against RNases, respectively. Dendriplexes were formed within $2 \mathrm{~h}$ of incubation and were treated with $0.2 \mathrm{UI} / \mu \mathrm{L}$ of heparin (Lab Ramón Sala, Barcelona, Spain) for $5 \mathrm{~min}$ at RT and/or $1 \mu \mathrm{g} / \mu \mathrm{L}$ of RNase (Promega, Madrid, Spain) for $10 \mathrm{~min}$ at RT and loaded as described before.

\section{Zeta potential and dynamic light scattering}

Surface charge and stability of the dendrimers and dendriplexes were studied by measuring the zeta potential (ZP) and their distribution analyzed measuring the hydrodynamic size (diameter) by dynamic light scattering (DLS).

Dendrimer and dendriplexes samples were prepared in nuclease-free water (Promega, Madrid, Spain) using the maximum non-toxic concentrations (G2-SN15-PEG $10 \mu \mathrm{M}$ and G3-SN15-PEG $5 \mu \mathrm{M}$ ) and hsa-miR-29A-3p $(100 \mathrm{nM})$. For ZP, samples were loaded into folded capillary cells and measured using a voltage of $100 \mathrm{~V}$. For DLS, samples were loaded into quartz cuvettes with pathlength $10 \mathrm{~mm}$. Measurements were performed at $25^{\circ} \mathrm{C}$ with a Zetasizer Nano ZS spectrometer (Malvern Instrument, Malvern, UK). Three measurements with fourteen cycles were made for each sample.

\section{Confocal microscopy}

Internalization of the dendrimers into cells was analyzed by confocal microscopy with a Leica TSC SPE Confocal Microscope (Leica, Wetzalar, Germany). 
PBMCs were seeded at a density of $1 \times 10^{6}$ cells/well in 24-well plates and U87MG-CD $4^{+} \mathrm{CCR} 5^{+}$cells were seeded at $7.5 \times 10^{3}$ cells in $12 \mathrm{~mm}$ circle cover slips (Thermo Fisher Scientific, Waltham, MA, USA) pretreated for $24 \mathrm{~h}$ with poly-L-Lysine (Sigma, St Louis, MO, USA). Cells were treated with the fluorescent dendrimers for $1 \mathrm{~h}, 2 \mathrm{~h}$ or $6 \mathrm{~h}$ at $37^{\circ} \mathrm{C}$. After incubation, handling PBMCs as suspension cells and U87MG$\mathrm{CD} 4{ }^{+} \mathrm{CCR}^{+}$as adherent cells, cells were rinsed twice with $3 \%$ bovine serum albumin (BSA, Sigma, St Louis, MO, USA) phosphate buffered saline (PBS, Lonza, Base, Switzerland), fixed with $4 \%$ paraformaldehyde (PFA, Panreac, Barcelona, Spain) and permeabilized with $0.1 \%$ Triton 100X (Sigma, St Louis, MO, USA) for 15 min. Cells were then incubated with Alexa Fluor ${ }^{\circledR}$ 555 Phalloidin (Thermo Fisher Scientific, Waltham, MA, USA) for $1 \mathrm{~h}$ at RT for actin labelling and then rinsed with PBS 3\% BSA. Lastly, cells were incubated with 4',6-Diamidino-2-phenylindole dihydrochloride (DAPI, Sigma, St Louis, MO, USA) for nuclear visualization and mounted in microscope slides (Dako, Carpinteria, CA, USA) with fluorescent mounting media (Dako, Carpinteria, CA, USA).

\section{Flow cytometry}

The internalization of FITC labelled dendrimers was confirmed by flow cytometry. Briefly, $1 \times 10^{6}$ PBMCs or $1.5 \times 10^{4}$ U87MG-CD4 ${ }^{+}$CCR $5^{+}$cells/well were seeded in 24-well plates and treated with the fluorescent dendrimers for 1,2 or $6 \mathrm{~h}$ at $37^{\circ} \mathrm{C}$. After incubation, adherent cells were removed by trypsinization and rinsed with PBS 3\% BSA. PBMCs were incubated with anti-CD3-PC5 (Beckman Coulter, Brea, CA, USA) for $30 \mathrm{~min}$ at RT and then rinsed with PBS 3\% BSA. Viability was assessed in both cell lines with 7-Aminoactinomycin D (7-AAD) (Sigma, St Louis, MO, USA) following manufacturer's instructions in both cell lines. Lastly, cells were fixed with $4 \%$ PFA. Measurements were analyzed using Kaluza software (Beckman Coulter, Brea, CA, USA).

\section{HIV-1 inhibition activity of the dendriplexes}

Inhibition experiments were carried out to test the antiR5-HIV-1 activity of the different dendriplexes. PBMCs were seeded at a density of $1 \times 10^{6}$ cells/well in 24-well plates and U87MG-CD4 ${ }^{+} \mathrm{CCR} 5^{+}$at $7.5 \times 10^{3}$ cells/well in 96-well plates. Afterwards, cells were infected with R5-HIV-1NL ${ }_{(\mathrm{AD} 8)}$ strain (15 ng p24/106 cells) and treated with the desired dendriplexes previously incubated for $2 \mathrm{~h}$ to allow the complex formation. $72 \mathrm{~h}$ after the infection, supernatants were collected and titrated or frozen at $-80^{\circ} \mathrm{C}$.

\section{Supernatant titration}

Viral infectivity was inferred by luciferase activity measurements performed following supernatant titration on TZM.bl cells with the previously collected supernatants. TZM.bl cells were seeded at a density of $1 \times 10^{4}$ cells/well in 96-well plates. Subsequently, medium was removed and replaced with $100 \mu \mathrm{L}$ of new medium and $100 \mu \mathrm{L}$ of supernatants from PBMCs or U87MG-CD $4{ }^{+} \mathrm{CCR}^{+}{ }^{+}$infected and treated cells. $48 \mathrm{~h}$ post-titration, medium was removed, and cells were lysed with $50 \mu \mathrm{L}$ of the Cell Culture Lysis $5 \mathrm{X}$ Reagent (Promega, Madrid Spain) for $30 \mathrm{~min}$ at $4^{\circ} \mathrm{C}$. Finally, 25 $\mu \mathrm{L}$ of the lysates were transferred to a white clear bottom plate and $25 \mu \mathrm{L}$ of Luciferase Assay Reagent (Promega, Madrid, Spain) were added right before reading the luciferase activity in a Synergy 4 plate reader at a $135 / 200 \mathrm{~nm}$.

\section{Statistics}

GraphPad software Prism v.5.0 (GraphPad Software, San Diego, CA, USA) was used for the different statistical analysis performed. Data with three replicates are displayed as bars \pm SD. A p-value of $\leq 0.05$ was considered to be statistically significant ("p $<0.05$; ${ }^{* *} \mathrm{p}<0.01$; **** $\mathrm{p}<0.001)$.

\section{Acknowledgements}

We would like to thank Vanessa Cañadilla Martín (Consejería de Educación e Investigación de la Comunidad de Madrid y Fondo Social Europeo (Grant no.: PEJ-2018-TL/BMD-11529)) and Patricia Pola for their expert technical assistance.

\section{Authors' contributions}

Study Design and Supervision: MFMA, JJL Experimental design: RII, RRE, MDM, $\mathrm{GR}^{*} \mathrm{LCT}^{*}, \mathrm{MFJ}^{*}$ ("provided the dendrimers), MFMA, JJL. Data acquisition: RII, RRE, MDM. Data analysis: RII, RRE, MDM, MFMA, JJL. Manuscript writing: RII, RRE, MFMA, JJL Manuscript editing: RII, RRE, MFMA, JL. All authors read and approved the final manuscript.

\section{Funding}

This work was (partially) supported by the RD16/0025/0019 projects as part of Acción Estratégica en Salud, Plan Nacional de Investigación Científica, Desarrollo e Innovación Tecnológica (2013-2016) and cofinanced by Instituto de Salud Carlos III (ISC-III-Subdirección General de Evaluación) and Fondo Europeo de Desarrollo Regional (FEDER), RETIC PT17/0015/0042, Fondo de Investigación Sanitaria (FIS) (PI19/01638, PI17/01115), EPIICAL project, CTQ2017-86224-P (MINECO), Comunidad de Madrid (B2017/BMD-3703; B2017/BMD-3733) and and project SBPLY/17/180501/000358 JCCM. CIBERBBN is an initiative funded by the VI National R\&D\&i Plan 2008-2011, Iniciativa Ingenio 2010, the Consolider Program, and CIBER Actions and financed by the ISC-III with assistance from the European Regional Development Fund (PIE14/00061). This work has been supported partially by a EUROPARTNER: Strengthening and spreading international partnership activities of the Faculty of Biology and Environmental Protection for interdisciplinary research and innovation of the University of Lodz Programme: NAWA International Academic Partnership Programme. This article/publication is based upon work from COST Action CA 17140 "Cancer Nanomedicine from the Bench to the Bedside" supported by COST (European Cooperation in Science and Technology). Programa de Investigación de la Consejería de Sanidad de la Comunidad de Madrid to JLJ. 
Availability of data and materials

Not applicable.

\section{Declarations}

Ethics approval and consent to participate

Not applicable.

\section{Consent for publication}

Not applicable.

\section{Competing interests}

The authors declare that they have no competing interests.

\section{Author details}

${ }^{1}$ Laboratorio InmunoBiología Molecular, Hospital General Universitario Gregorio Marañón (HGUGM), Instituto Investigación Sanitaria Gregorio Marañón (IiSGM), Spanish HIV HGM BioBanco, Madrid, Spain. ${ }^{2}$ Plataforma de Laboratorio (Inmunología), HGUGM, liSGM, Spanish HIV HGM BioBank, Madrid, Spain. ${ }^{3}$ Laboratorio Dosimetría Biológica, HGUGM, liSGM, Madrid, Spain. ${ }^{4}$ Departmento Química Orgánica Y Química Inorgánica E Instituto de Investigación Química "Andrés M. del Río" (IQAR), Universidad de Alcalá (IRYCIS), Campus Universitario, 28871 Madrid, Spain. ${ }^{5}$ Networking Research Center On Bioengineering, Biomaterials and Nanomedicine (CIBER-BBN, Madrid, Spain.

Received: 17 January 2021 Accepted: 18 May 2021

Published online: 28 May 2021

\section{References}

1. Bissel SJ, Wiley CA. Human immunodeficiency virus infection of the brain: pitfalls in evaluating infected/affected cell populations. Brain Pathol. 2004;14(1):97-108.

2. Zayyad Z, Spudich S. Neuropathogenesis of HIV: from initial neuroinvasion to HIV-associated neurocognitive disorder (HAND). Curr HIV/AIDS Rep. 2015;12(1):16-24.

3. A I. Guidelines for the use of antiretroviral agents in adults and adolescents living with HIV. . Department of Health and Human Services; 2019 [updated 10 July 2019]. https://aidsinfo.nih.gov/guidelines/html/1/adultand-adolescent-arv/0.

4. EAC S. Guidelines for the clinical management and treatment of HIVinfected adults in Europe. 2018. https://www.eacsociety.org/guidelines/.

5. Diallo M, Adekpedjou R, Ahouada C, Ngangue P, Ly BA. Impact of preantiretroviral therapy CD4 counts on drug resistance and treatment failure: a systematic review. AIDS Rev. 2020:22(2):78-92.

6. Inzaule SC, Jordan MR, Bello G, Wadonda-Kabondo N, Mounerou S, Mbulli IA, et al. High levels of resistance to nucleoside/nucleotide reverse transcriptase inhibitors in newly diagnosed antiretroviral treatment-naive children in sub-Saharan Africa. AIDS. 2020;34(10):1567-70.

7. Sylla M, Dolo O, Maiga Al, Traore FT, Coulibaly YA, Togo J, et al. Second-line antiretroviral therapy failure and characterization of HIV-1 drug resistance patterns in children in Mali. Arch Pediatr. 2019;26(5):254-8.

8. Cantero-Perez J, Grau-Exposito J, Serra-Peinado C, Rosero DA, Luque-Ballesteros L, Astorga-Gamaza A, et al. Resident memory T cells are a cellular reservoir for HIV in the cervical mucosa. Nat Commun. 2019;10(1):4739.

9. Chatzidimitriou D, Tsotridou E, Grigoropoulos P, Skoura L. HIV-1: towards understanding the nature and quantifying the latent reservoir. Acta Virol. 2020;64(1):3-9.

10. Reeves DB, Duke ER, Wagner TA, Palmer SE, Spivak AM, Schiffer JT. A majority of HIV persistence during antiretroviral therapy is due to infected cell proliferation. Nat Commun. 2018;9(1):4811.

11. Wallet C, De Rovere M, Van Assche J, Daouad F, De Wit S, Gautier V, et al. Microglial cells: the main HIV-1 reservoir in the brain. Front Cell Infect Microbiol. 2019;9:362.

12. Dahlman JE, Barnes C, Khan O, Thiriot A, Jhunjunwala S, Shaw TE, et al. In vivo endothelial siRNA delivery using polymeric nanoparticles with low molecular weight. Nat Nanotechnol. 2014;9(8):648-55.
13. Ratajczak K, Krazinski BE, Kowalczyk AE, Dworakowska B, Jakiela S, Stobiecka M. Optical biosensing system for the detection of survivin mRNA in colorectal cancer cells using a graphene oxide carrier-bound oligonucleotide molecular beacon. Nanomaterials (Basel). 2018;8(7):510.

14. Song WJ, Du JZ, Sun TM, Zhang PZ, Wang J. Gold nanoparticles capped with polyethyleneimine for enhanced siRNA delivery. Small. 2010;6(2):239-46.

15. Stobiecka M, Hepel M. Double-shell gold nanoparticle-based DNA-carriers with poly-L-lysine binding surface. Biomaterials. 2011:32(12):3312-21.

16. Cena-Diez R, Martin-Moreno A, de la Mata FJ, Gomez-Ramirez R, Munoz E, Ardoy M, et al. G1-S4 or G2-S16 carbosilane dendrimer in combination with Platycodin D as a promising vaginal microbicide candidate with contraceptive activity. Int J Nanomedicine. 2019;14:2371-81.

17. Genebat M, Tarancon-Diez L, Pulido I, Alvarez-Rios Al, Munoz-Fernandez MA, Ruiz-Mateos E, et al. Hepatitis C virus and cumulative infections are associated with atherogenic cardiovascular events in HIV-infected subjects. Antiviral Res. 2019;169:104527.

18. Guerrero-Beltran C, Rodriguez-Izquierdo I, Serramia MJ, Araya-Duran I, Marquez-Miranda V, Gomez R, et al. Anionic carbosilane dendrimers destabilize the GP120-CD4 complex blocking HIV-1 entry and cell to cell fusion. Bioconjug Chem. 2018;29(5):1584-94.

19. Relano-Rodriguez I, Juarez-Sanchez R, Pavicic C, Munoz E, MunozFernandez MA. Polyanionic carbosilane dendrimers as a new adjuvant in combination with latency reversal agents for HIV treatment. J Nanobiotechnology. 2019;17(1):69.

20. Sepulveda-Crespo D, de la Mata FJ, Gomez R, Munoz-Fernandez MA. Sulfonate-ended carbosilane dendrimers with a flexible scaffold cause inactivation of HIV-1 virions and gp120 shedding. Nanoscale. 2018;10(19):8998-9011.

21. Bermejo JF, Ortega P, Chonco L, Eritja R, Samaniego R, Mullner M, et al. Water-soluble carbosilane dendrimers: synthesis biocompatibility and complexation with oligonucleotides; evaluation for medical applications. Chemistry. 2007;13(2):483-95.

22. Gonzalo T, Clemente MI, Chonco L, Weber ND, Diaz L, Serramia MJ, et al. Gene therapy in HIV-infected cells to decrease viral impact by using an alternative delivery method. ChemMedChem. 2010;5(6):921-9.

23. Perise-Barrios AJ, Jimenez JL, Dominguez-Soto A, de la Mata FJ, Corbi AL, Gomez R, et al. Carbosilane dendrimers as gene delivery agents for the treatment of HIV infection. J Control Release. 2014;28(184):51-7.

24. Weber N, Ortega P, Clemente MI, Shcharbin D, Bryszewska M, de la Mata FJ, et al. Characterization of carbosilane dendrimers as effective carriers of siRNA to HIV-infected lymphocytes. J Control Release. 2008;132(1):55-64.

25. Palmerston Mendes L, Pan J, Torchilin VP. Dendrimers as nanocarriers for nucleic acid and drug delivery in cancer therapy. Molecules. 2017;22(9):1401.

26. Balasubramaniam M, Pandhare J, Dash C. Are microRNAs important players in HIV-1 infection? An update. Viruses. 2018;10(3):110.

27. Gulyaeva LF, Kushlinskiy NE. Regulatory mechanisms of microRNA expression. J Transl Med. 2016;14(1):143.

28. Huang J, Wang F, Argyris E, Chen K, Liang Z, Tian H, et al. Cellular microRNAs contribute to HIV-1 latency in resting primary CD4+ T lymphocytes. Nat Med. 2007;13(10):1241-7.

29. Nathans $R$, Chu CY, Serquina AK, Lu CC, Cao H, Rana TM. Cellular microRNA and P bodies modulate host-HIV-1 interactions. Mol Cell. 2009;34(6):696-709.

30. Swaminathan G, Navas-Martin S, Martin-Garcia J. MicroRNAs and HIV-1 infection: antiviral activities and beyond. J Mol Biol. 2014;426(6):1178-97.

31. Whitehead KA, Langer $R$, Anderson DG. Knocking down barriers: advances in siRNA delivery. Nat Rev Drug Discov. 2009;8(2):129-38.

32. Suk JS, Xu Q, Kim N, Hanes J, Ensign LM. PEGylation as a strategy for improving nanoparticle-based drug and gene delivery. Adv Drug Deliv Rev. 2016;99(Pt A):28-51.

33. Ahluwalia JK, Khan SZ, Soni K, Rawat P, Gupta A, Hariharan M, et al. Human cellular microRNA hsa-miR-29a interferes with viral nef protein expression and HIV-1 replication. Retrovirology. 2008;23(5):117.

34. Houzet L, Klase Z, Yeung ML, Wu A, Le SY, Quinones M, et al. The extent of sequence complementarity correlates with the potency of cellular miRNA-mediated restriction of HIV-1. Nucleic Acids Res. 2012:40(22):11684-96.

35. Gonzalez-Beltran F, Morales-Ramirez P. In vivo repair during G1 of DNA lesions eliciting sister chromatid exchanges induced by 
methylnitrosourea or ethylnitrosourea in BrdU substituted or unsubstituted DNA in murine salivary gland cells. Mutat Res. 1999;425(2):239-47.

36. Gonzalez-Beltran F, Morales-Ramirez P. Repairability during G1 of lesions eliciting sister chromatid exchanges induced by methylmethanesulfonate or ethylmethanesulfonate in bromodeoxyuridine-substituted and unsubstituted DNA strands. Mutagenesis. 2003;18(1):13-7.

37. Matsuoka A, Lundin C, Johansson F, Sahlin M, Fukuhara K, Sjoberg $\mathrm{BM}$, et al. Correlation of sister chromatid exchange formation through homologous recombination with ribonucleotide reductase inhibition. Mutat Res. 2004;547(1-2):101-7.

38. Laskey SB, Siliciano RF. A mechanistic theory to explain the efficacy of antiretroviral therapy. Nat Rev Microbiol. 2014;12(11):772-80.

39. Saylor D, Dickens AM, Sacktor N, Haughey N, Slusher B, Pletnikov M, et al. HIV-associated neurocognitive disorder-pathogenesis and prospects for treatment. Nat Rev Neurol. 2016;12(4):234-48.

40. Blankson JN, Persaud D, Siliciano RF. The challenge of viral reservoirs in HIV-1 infection. Annu Rev Med. 2002;53:557-93.

41. Clutter DS, Jordan MR, Bertagnolio S, Shafer RW. HIV-1 drug resistance and resistance testing. Infect Genet Evol. 2016;46:292-307.

42. Pierson T, McArthur J, Siliciano RF. Reservoirs for HIV-1: mechanisms for viral persistence in the presence of antiviral immune responses and antiretroviral therapy. Annu Rev Immunol. 2000;18:665-708.

43. Taylor BS, Hammer SM. The challenge of HIV-1 subtype diversity. N Engl J Med. 2008;359(18):1965-6.

44. Rodriguez-Izquierdo I, Natalia C, Garcia F, Los Angeles Munoz-Fernandez M. G2-S16 sulfonate dendrimer as new therapy for treatment failure in HIV-1 entry inhibitors. Nanomedicine. 2019;14(9):1095-107.

45. Sepulveda-Crespo D, Serramia MJ, Tager AM, Vrbanac V, Gomez R, De La Mata FJ, et al. Prevention vaginally of HIV-1 transmission in humanized
BLT mice and mode of antiviral action of polyanionic carbosilane dendrimer G2-S16. Nanomedicine. 2015;1 1(6):1299-308.

46. Jain K, Kesharwani P, Gupta U, Jain NK. Dendrimer toxicity: let's meet the challenge. Int J Pharm. 2010;394(1-2):122-42.

47. Liu X, Rocchi P, Peng L. Dendrimers as non-viral vectors for siRNA delivery. New J Chem. 2012;36(2):256-63.

48. Somani S, Laskar P, Altwaijry N, Kewcharoenvong P, Irving C, Robb G, et al. PEGylation of polypropylenimine dendrimers: effects on cytotoxicity, DNA condensation, gene delivery and expression in cancer cells. Sci Rep. 2018;8(1):9410.

49. Albertazzi L, Serresi M, Albanese A, Beltram F. Dendrimer internalization and intracellular trafficking in living cells. Mol Pharm. 2010;7(3):680-8.

50. Wei X, Decker JM, Liu H, Zhang Z, Arani RB, Kilby JM, et al. Emergence of resistant human immunodeficiency virus type 1 in patients receiving fusion inhibitor (T-20) monotherapy. Antimicrob Agents Chemother. 2002;46(6):1896-905.

51. Garcia-Merino I, de Las CN, Jimenez JL, Gallego J, Gomez C, Prieto C, et al. The Spanish HIV BioBank: a model of cooperative HIV research. Retrovirology. 2009;9(6):27.

52. Garcia-Broncano P, Cena-Diez R, de la Mata FJ, Gomez R, Resino S, MunozFernandez MA. Efficacy of carbosilane dendrimers with an antiretroviral combination against HIV-1 in the presence of semen-derived enhancer of viral infection. Eur J Pharmacol. 2017;15(811):155-63.

\section{Publisher's Note}

Springer Nature remains neutral with regard to jurisdictional claims in published maps and institutional affiliations.
Ready to submit your research? Choose BMC and benefit from:

- fast, convenient online submission

- thorough peer review by experienced researchers in your field

- rapid publication on acceptance

- support for research data, including large and complex data types

- gold Open Access which fosters wider collaboration and increased citations

- maximum visibility for your research: over 100M website views per year

At BMC, research is always in progress.

Learn more biomedcentral.com/submissions 